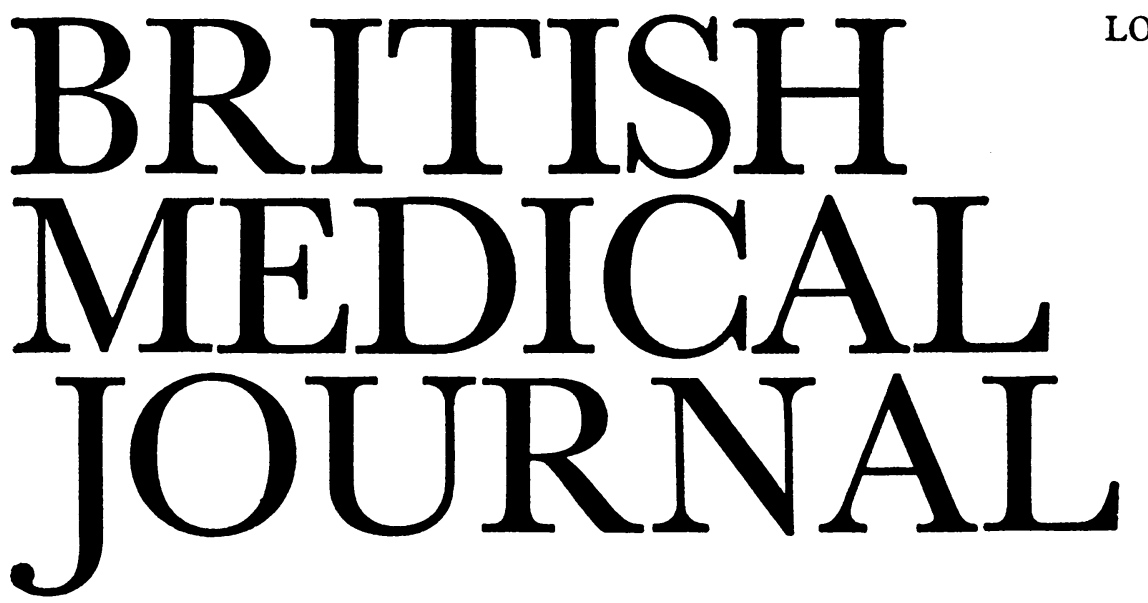

LONDON, SATURDAY 18 OCTOBER 1975

\title{
Hyperactivity in children
}

It has been known for many years that brain-injured children tend to be overactive, ${ }^{1}$ but it is only recently that such behaviour has become synonymous with a syndrome-the hyperkinetic syndrome. ${ }^{2}$ This is characterised as a chronic, sustained, excessive level of motor activity relative to the age of the child, occurring mainly in boys between 1 and 16 years, but characteristically around 6 years, accompanied by short attention span, impulsive behaviour or explosive outbursts, and causing substantial complaints at home or in school.

The symptoms of hyperactivity apparently respond to the use of amphetamines, resulting in diminished activity, better attention, and concentration ${ }^{3}$-an unexpected effect in view of the stimulant effects of the amphetamines, but one that is well authenticated..$^{4-7}$ In turn, this has given rise to research and to theories ${ }^{8-12}$ implying that these children have insufficient inhibitory controls over motor outflow and sensory input to their brains, resulting in flooding by sensory signals from within and without which trigger continuous responses. ${ }^{13}$ This process, it is argued, is reversed by central stimulants, which increase the arousal of the brain and increase inhibitions, resulting in improved behaviour and learning. ${ }^{14} 15$ The research from which these theories have flowed has concerned brain dysfunction of many causes-premature birth, ${ }^{16}$ perinatal abnormalities, ${ }^{17}$ and temporal lobe epilepsy. ${ }^{18}$ Increasingly, hyperkinesis has come to be regarded as synonymous with brain damage or minimal brain dysfunction, whether unequivocal neurological signs are present or not. As a result children thought to show evidence of the syndrome have been automatically treated by one or other of the stimulant drugs.

It has been especially in the United States that there has been an enthusiastic use of the diagnosis of the hyperkinetic syndrome or minimal brain damage and an equally enthusiastic use of stimulant drugs. Child psychiatrists in Washington labelled $40 \%$ of the children they saw as hyperkinetic in one survey, ${ }^{19}$ and in another $70 \%$ of such children were prescribed stimulant drugs. ${ }^{20}$ Indeed, 200000 children in the United States are currently receiving stimulant drugs without, it is claimed, the habituation and the abuse problems seen in the older age group.

Attitudes towards overactive behaviour in children differ appreciably on this side of the Atlantic. Though the hyperkinetic syndrome is a recognised entity, it is diagnosed far more rarely, being found in only $1.6 \%$ of all psychiatrically disordered children of 9-11 years in a survey in the Isle of
Wight, ${ }^{21}$ and usually co-existing with other handicapping conditions such as mental retardation or childhood psychosis. Fewer children are labelled hyperkinetic and fewer are prescribed amphetamines.

What can account for such differences? Is it ignorance about a treatable condition, and the withholding of a powerful and effective treatment, or is it a difference in interpretation and understanding of the problem? Epidemiological surveys of children's behaviour do in fact show that "overactive," restless behaviour in children is a frequent complaint. Half of the mothers in an American survey ${ }^{22}$ considered their 6 to 8 year old boys to be overactive, while $35 \%$ of mothers of 9 to 11 year old boys in England considered their children to be abnormally restless. ${ }^{21}$ When children with restlessness and hyperactivity show signs of psychiatric disturbance such as aggressiveness and antisocial behaviour the cause is more often to be found in a disturbed family background or failure of early care ${ }^{23}$ than unequivocal brain damage. Proved brain damage may cause the child to be more vulnerable to stress in the environment but it does not specifically lead to overactivity. ${ }^{24}$ Indeed, comparisons between hyperactive neurologically impaired children and controls with conduct disorders show little difference in activity levels on a number of measures. ${ }^{25}$ This suggests that there may be different mechanisms producing hyperactive behaviour ${ }^{26}$ which can be obscured if it is assumed that overactive behaviour is caused only by brain damage. Recent research has indicated that genetic temperamental mechanisms may be operative. ${ }^{27}$ It may also be wishful thinking to consider that any drug alone could affect such a difficult problem as the chronically overactive child. ${ }^{28}$

Other research also throws doubt on the overeasy assumption that brain damage leads to abnormal behaviour (and vice versa). Even unequivocal brain damage at birth need not result in later behavioural and intellectual abnormality provided that parent-infant relationships are optimal. ${ }^{23}$ Furthermore environmental factors around the time of the birth-separation or abnormal emotional states in the mother-can be as potent a cause of failure in mother-infant relations and later disturbed behaviour ${ }^{29}$ as biological factors.

The practitioner presented with a family complaining of a child's high activity level together with poor attention span and impulsiveness, behavioural problems, and learning difficulties should first ascertain from his own observations and those of the child's teacher or nursery school or play group whether 
the child stands out from his peers in this respect. If not, then the problem can be dealt with as a family response to a particular characteristic of the child's maturation with a need for adaptation, understanding, and tolerance. If it is clear that the child has an unusual degree of activity then specialist paediatric or child-psychiatric help will be necessary to distinguish between the rare child with a true hyperkinetic syndrome and the child who is responding to emotional, environmental, or psychiatric causes.

Management may well require a wide variety of diagnostic and treatment facilities. The true hyperkinetic child does require drugs, and it has recently been shown that L-amphetamine with its more sedative central effects may be more potent than D-amphetamine ${ }^{30}$ in effect. Methylphenidate is also effective; caffeine derivatives, ${ }^{31}$ antidepressants, phenothiazines, or haloperidol can also be tried as an alternative to amphetamine. Whichever drug is given it should be in the minimal effective dose and sometimes the patient should be taken off it. Follow-up ${ }^{32}$ indicates that amphetamines continue to be effective but that despite a general improvement with age the drug gives only symptomatic relief, and general improvement and maturation of the child depend to a great extent on the normality or abnormality of the family. Growth is affected by long-term use of amphetamines, and the drug should be withheld for a year or two before epiphyseal closure.

The family requires much help and counselling with its own responses to the child's behavioural problems to reduce secondary handicaps. Families do not always welcome the change in the child's personality with drugs. He may become less active but more miserable, ${ }^{33}$ or if he has become a family scapegoat other problems may then emerge in a sibling or in the marital relationship.

A preschool day centre ${ }^{34}$ or nursery may be necessary to help the young child and his family, and a special school ${ }^{35}$ or day centre may be needed for the older child. Such treatment may well need to be combined with some other techniques with the family or the individual-dynamic or behavioural. ${ }^{36-38}$ One area of contention is whether the use of drugs is justified in the child whose overactivity and restlessness is related to emotional or environmental causes. The drugs, it is said, may lessen the troublesome symptoms and possibly enable the family to be helped. This is an attractive argument, but there is a danger of colluding with the family's natural wish to lessen its own sense of guilt and responsibility, thus falling into the trap of providing a syndrome, a cause, and a drug treatment rather than treatment for the whole family when needed.

1 Still, G F, Lancet, 1902, 1, 1008, 1077, 1163.

2 Strauss, A A, and Lehtinen, L, Psychopathology and Education of the Brain Injured Child. New York, Grune and Stratton, 1947.

${ }^{3}$ Bradley, C, American fournal of Psychiatry, 1937, 94, 577.

${ }^{4}$ Eisenberg, L, Pediatrics, 1972, 49, 709.

5 Millichap, J G, Annals of the New York Academy of Sciences, 1973, 205, 321.

6 Sroufe, L A, and Stewart, M A, New England fournal of Medicine, 1973, 289, 407.

7 Connors, C K, Excerpta Medica International Congress Series 313, 1974

${ }^{8}$ Laufer, M W, Denhoff, E, and Solomons, S G, Psychosomatic Medicine, $1957,19,38$.

${ }^{9}$ Shetty, T, Nature, 1971, 234, 476.

${ }^{10}$ Connors, C K, and Rothschild, G H, Abnormal Child Psychology, 1973.

$1,16$.
11 Werry, J, Sprague, R, and Weiss, B, in Drugs and Cerebral Function, ed W L Smith. Springfield, Thomas, 1970.

12 Wender, P H, Minimal Brain Dysfunction in Children. New York, Wiley, 1971.

13 Satterfield, J H, Cantwell, D P, and Satterfield, B T, Archives of General Psychiatry, 1974, 31, 839.

14 Connors, $\mathrm{C} \mathrm{K}$, and Rothschild, G H, in Learning Disorders, ed J Hellmuth. Seattle, Straub and Hellmuth, 1968.

15 Sprague, R L, Barnes, K R, and Werry, J S, American fournal of Orthopsychiatry, 1970, 40, 615.
16 Drillien, C M, in Recent Advances in Paediatrics, 3rd edn, ed D Gairdner and D Hull. London, Churchill, 1965.

17 Pasamanick, B, and Knobloch, H, American fournal of Orthopsychiatry, 1960, 30, 298.

18 Ounsted, L, Lindsay, J, and Norman, R, Biological Factors in Temporal Lobe Epilepsy, Clinics in Developmental Medicine No 22. London, Heinemann, 1966.

19 Greenberg, L, and Lipman, R, Clinical Proceedings of the Children's Hospital, Washington, 1971, 27, 101.

${ }^{20}$ Steven, K U, Sprague, R L, and Werry, J S, Drug Treatment of Children in Chicago in Progress Report of Grant M H 18909. Children's Research Centre, University of Illinois, Urbana Champaign, 1973.

21 Rutter, M, Tizard, J, and Whitmore, K, Education, Health and Behaviour London, Longman, 1970.

${ }^{22}$ Lapouse, R, and Monk, M A, American Fournal of Public Health, 1958, 48, 1134.

${ }^{23}$ Rutter, M, Fournal of Child Psychology and Psychiatry and Allied Disciplines, 1971, 12, 233.

24 Rutter, M, Graham, P, and Yule, W, A Neuropsychiatric Study in Childhood. Clinics in Developmental Medicine 356. London, Heinemann, 1970.

${ }^{25}$ Shaffer, D R, McNamara, N, and Pincus, J H, Fournal of Psychological Medicine, 1974, 4, 4.

${ }^{26}$ Montagu, J D, Developmental Medicine and Child Neurology, 1975, 17, 299.

27 Cantwell, D P, Fournal of Child Psychology and Psychiatry and Allied Disorders, 1975, 16, 261.

28 Fish, B, Archives of General Psychiatry, 1971, 25, 193.

29 Sameroff, A J, and Chandler, M J, in Review of Child Development Research (4). Chicago, University of Chiacgo, 1975.

${ }^{30}$ Montagu, J D, and Swarbreck, L, Developmental Medicine and Child Neurology, 1975, 17, 293.

31 Schnackenberg, R C, American fournal of Psychiatry, 1973, 130, 796.

32 Conners, C K, in Psychopathological Disorders in Childhood, ed H C Quay and J S Werry. New York, Wiley, 1972.

${ }^{33}$ Barcai, A, fournal of Child Psychology and Psychiatry and Allied Disorders, $1969,10,269$.

${ }^{34}$ Bentovim, A, and Lansdown, R, British Medical fournal, 1973, 4, 536.

35 Minde, K, et al, Exceptional Children, 1971, 38, 215.

36 Minuchin, S, Families and Family Therapy. London, Tavistock, 1974.

37 Patterson, G R, in Case Studies in Behaviour Modification, eds L Ullman and L Krasner. New York, Holt, Rinehart and Winston, 1965.

${ }^{38}$ Furman, S, and Feighner, A, American fournal of Psychiatry, 1973, 130 792.

\section{Family planning prospects}

The children born during the baby boom of the late 1950s and early ' 60 s are now entering their reproductive years, and they will be under strong pressure from their contemporaries and the pop-culture to regard sex as an essential part of social activity. Whether or not teenage sexual adventures have adverse psychological effects is far from clear, but there is no doubt of the dangers of sexually transmitted disease or of the high incidence of unwanted pregnancies in this age group. Advice on contraception and indeed all aspects of sexual behaviour should be readily available to these youngsters; will the NHS be able to provide it?

The Family Planning Association clinics, which until recently provided the basis of medical contraceptive services in Britain, have now mostly been transferred to NHS health authorities, smoothly and apparently successfully. Voluntary workers are being offered NHS contracts, and for the time being the cost of the service is being underwritten by the Department of Health. Nevertheless, as the lean years ahead force area health authorities to accept cuts in their budgets ${ }^{1}$ these clinics may become a target for economies, and it would be a tragic irony if the well-intentioned State takeover of family planning clinics led to their decline rather than their expansion.

Just as important as the clinics run by the FPA was the training in contraceptive methods it provided for doctors. As the era of the cap and jelly fades into history, proper training becomes of even greater importance: hormonal contraceptives and IUDs may have serious side effects-and even cause death. Moreover, effects that are acceptable as a consequence 